\title{
Confluencia y enfrentamiento de tradiciones en los albores del cristianismo
}

\author{
Herón Pérez Martínez*
}

\author{
Recibido: Julio 2011 • Aceptado: Setiembre 2011
}

\section{RESUMEN}

Es un estudio sobre las tradiciones cristianas de los dos primeros siglos, que conforman el Nuevo Testamento. Estos libros sagrados constituyen el canon, calificación posterior al nacimiento de los mismos. Se busca en este estudio indagar y presentar los principales postulados de la investigación y de la desmitificación bíblica de los últimos cien años.

Palabras clave: Tradiciones cristianas. Nuevo Testamento. Canon. Libros sagrados. Ambiente vital. Mitos. Desmitificación. Corpus Paulinum. Qumrán. Jesús histórico. Jesús de la fe.

\section{ABSTRACT}

This is a study about the Christian traditions from the firs centuries, which make the Christian traditions. These sacred books establish the canon, score after the born of those. It is been seek along this study to ask and present the main postulates of the investigation and of the biblical demystification from the last years.

Key words: Christian traditions. Christian traditions. Canon. Sacred books. Vital environment. Myths. Demystification. Corpus Paulinum. Qumrán. Historic Jesus. Jesus of Faith.

* Doctor en Letras con especialidad en lenguas románicas, por la Universidad de Bourgogne, Francia. Tiene una Licenciatura en Teología de la Universidad Gregoriana y Maestría en Estudios Bíblicos del Instituto Bíblico de Roma. Miembro de la Academia Mexicana de Ciencias y de la Lengua. Actualmente es profesor catedrático del Colegio de Michoacán, México. 


\section{El Nuevo Testamento y su índole ${ }^{1}$}

La tradición cristiana llama Nuevo Testamento a 27 obras de la época cristiana que considera sagradas y como la última revelación divina, palabra de Dios, puesta por escrito entre mediados del siglo I y principios del II siglo de nuestra era. Es una obra de propaganda con que los primeros cristianos trataban de convencer a sus lectores. A en ese conjunto de escritos, se llamó Nuevo Testamento para contraponerlo y distinguirlo del Antiguo Testamento, como se conocen a los textos sagrados antes de la era cristiana. ${ }^{2}$ En los libros del Nuevo Testamento, que tienen como libros sagrados, creen encontrar la verdad y si se cree en ellos, se alcanzará la salvación. El Nuevo Testamento es un conjunto voluntariamente cerrado de libros: su lista es lo que constituye el canon o lista de obras que debían tenerse como sagradas. Esa calificación, sin embargo, es una etiqueta externa: la mayoría de los

1. La bibliografía sobre este tema es muy numerosa. Invito al lector a leer a Antonio Piñero (editor), Orígenes del Cristianismo. Antecedentes y primeros pasos, Madrid, Ediciones el Almendro / Universidad Complutense de Madrid, 1991.

2. Para este apartado me sirvo principalmente del libro de Antonio Piñero Guía para entender el Nuevo Testamento, Madrid, Trotta, 2006. Aunque la bibliografía es muy abundante escritos contenidos en el N. T. no se presentan a sí mismos como "palabra de Dios". Son narraciones, explicaciones religiosas y escritos de circunstancias como cartas.

El Nuevo Testamento es una obra de autoría plural y comunitaria que se fue haciendo lentamente, a lo largo de los primeros 2 siglos, conforme los cristianos de la gran comunidad iban confirmando su conciencia como grupo distinto del judaísmo y los otros grupos que se fueron formando en torno al acontecimiento de Jesús de $\mathrm{Na}$ zaret. El Nuevo Testamento es una obra literaria, como el A. T., que empezó primero en forma de tradiciones orales en una variedad de géneros determinados por su función: como la obra homérica o $E l$ poema de Mio Cid. Esta fase oral se conformó por textos nacidos para satisfacer las necesidades que iban surgiendo. Las tradiciones orales fueron más fuertes e importantes en toda la fase de consolidación en textos escritos. Los textos escritos suplieron la ausencia de los testigos oculares conforme se fueron muriendo, a partir de la segunda mital del siglo I. En todo caso el surgimiento de la tradición escrita no canceló la tradición oral, ni la rompió: la tradición oral, anterior a la escrita, continuó desarrollándose de manera paralela. El hecho mismo de que recogieran en textos escritos los principales elementos revela un 
profundo respeto por la tradición oral: a veces mayor que el que se guardaba a los textos escritos.

Así, todo el Nuevo Testamento está conformado por pedacería que en otro tiempo cumplía una serie de funciones que aún nos dejan ver cual era la vida social de las comunidades cristianas primitivas. La historia de las formas nos ha enseñado no sólo a descubrir las funciones literarias que esos pequeños textos orales tuvieron sino el Sitz im Leben, el ambiente vital, en el cual nació cada pequeño texto: el relato de un milagro, una enseñanza o una plegaria del tipo que sea. ${ }^{3}$

\section{Postulados sobre los orígenes del Nuevo Testamento ${ }^{4}$}

A partir de la investigación bíblica de los últimos cien años, no sólo se han deslavado las autorías, las dataciones tradicionales, sino los parentescos y cercanías a otras

3. Véase Martín Dibelius, La historia de las formas evangélicas, Valencia, EDICEP, 1984. Rudolf Bultmann, La historia de la tradición sinóptica, Salamanca, Sígueme, 1995. Es una traducción del célebre libro de Bultmann Die Gescgichte der synoptischen Tradition, Göttingen, 1967. Karl Ludwig Schmidt, Der Rahmen der Geschichte Jesu, Darmstadt, Wissenschaftliche, Buchgesellschaft, 1969.

4. Hay una gran cantidad de obras que muestran el gestarse lento del Nuevo Testamento aquí quiero citar sólo a Daniel Marguerat (Ed.), Introducción al Nuevo Testamento. Su historia, su escritura, su teología, Bilbao, Desclée de Brouwer, 2008. tradiciones literarias que desmitifican muchas de las concepciones recibidas y transmitidas a lo largo de la historia. El Nuevo Testamento nace de la vida de cada día y de las necesidades de ir conformando una comunidad en torno a una fe en personaje como Jesús de Nazaret. He aquí algunos postulados que aferran esa realidad.

1.- Las obras que constituyen el N. T. son, casi todas, anónimas. Aunque cada uno de los escritos que componen el N. T. llevan el nombre de un autor, tal atribución es discutible y, en todo caso, engañosa porque, o bien nada se sabe del autor al que se atribuye, o bien la atribución es errónea. Sólo siete de las catorce cartas que conforman el llamado corpus paulino llevan indicios y datos de su autor: Pablo de Tarso: Flp, 1 y 2 Cor, Rom, Gal, 1 Tes y Film. Todas las cartas de Pablo que se han conservado fueron escritas en la primera mitad de la década de los 50. ${ }^{5}$ En la disposición actual hay, como se ve, un cierto revoltijo entre cartas auténticamente paulinas y otras que fueron escritas por discípulos (pseudónimas). ${ }^{6}$

\footnotetext{
5. Senén Vidal, El primer escrito cristiano, Salamanca, Ed. Sígueme, 2006.

6. Margaret y. Macdonald, Las comunidades paulinas, Salamanca, Sígueme, 1994.
} 
2.- Así, por ejemplo, Efesios refleja una mentalidad, cuyo destinatario, tanto como su autor, crearon dudas; va colocada entre Gal. y Fil. de la misma línea teológica. ${ }^{7}$ Las otras 7 cartas no son auténticas: son escritos posteriores a $\mathrm{Pa}-$ blo. Pertenecen a lo que podríamos llamar la "escuela paulina y son: 2 Tes, Col, Ef, 1,2 Tim. y Tit". La llamada Carta a los Heb, ya se sabe, sólo tiene las marcas epistolares que la época y la comunidad primitiva ponían a los textos que circulaban, como este sermón, entre sus miembros. Heb sólo con mucha dificultad, y muy tardíamente, fue aceptada en el corpus paulinum e incluso su ingreso al canon, reticente y muy tardía, se debe principalmente a la aceptación de la iglesia griega. Es de fines del siglo I. Todas estas cartas reflejan unas fechas que van desde fines del siglo I hasta ya bien entrado el siglo II. Muerto Pablo en el año 64, se conformaron una serie de "comunidades paulinas" que conservaron las estructuras, la doctrina, las enseñanzas y el ambiente paulino. ${ }^{8}$

7. Véase, a este respecto, Senén Vidal, Las cartas originales de Pablo, Madrid, Trotta, 1996.

8. Para esto véase especialmente Margaret Y Macdonald, Las comunidades paulinas, Salamanca, Sígueme, 1994. La autora analiza especialmente ese contexto como el que dio origen a Colosenses y Efesios.
3.- Muchas de las glosas, adiciones, y alteraciones a los textos paulinos y las creaciones de textos son hechas en nombre de un Pablo ya muerto hace años. El paulinismo, por ejemplo, que reflejan estas cartas es distinto del de las cartas auténticas. El contexto en el que nace y se recibe esta literatura no hay especialmente perspicacias sobre la autoría; el cristianismo primitivo no tenía especial afán crítico para establecer con exactitud si los autores a quienes se atribuían todas las obras del canon eran verdaderamente sus autores. ${ }^{9}$ Más aún, el concepto de autoría de esos momentos es radicalmente diferente al concepto actual. ${ }^{10}$

4.- Por no ser la obra de un solo autor, en el N. T. no sólo hay diversos estilos sino también posiciones y puntos de vista sostenidos, que no sólo son diferentes sino, en muchos casos, contradictorios. Cada autor, en efecto, refleja de alguna manera tanto su perspectiva, sus intenciones literarias tanto como sus circunstancias y sus puntos de vista tanto personales como los de su época. En algunos casos la situación que les subyace es diferente a la situación simulada por el texto.

\footnotetext{
9. Véase Jordi Sánchez Bosch, Escritos paulinos, Estella, 1998.

10. Véase Jordi Sánchez Bosch, Escritos paulinos, Estella, Verbo divino, 1998.
} 
Sin necesidad de poner muchos ejemplos, bien pueden ilustrar este carácter divergente, individualizante y autónomo de sus textos, el problema de la fecha y significado de la muerte de Jesús entre los sinópticos y el IV evangelio.

\section{5.- Un ejemplo de contradicción entre textos del Nuevo Testamento.} En efecto, según los sinópticos, Jesús celebró la cena pascual la tarde del jueves 14 de Nisán al comenzar, por tanto, el 15 Nisán: como se sabe, el día judío empieza a la puesta del sol. Ésto es lo que se desprende de Mc, el segundo evangelio al que, como se sabe, siguen en ésto los otros dos sinópticos:

Y el día primero de los Ázimos, cuando sacrificaba la Pascua, dicenle sus discípulos: ¿a dónde quieres que vayamos a prepararte lo necesario para comer la Pascua? $Y$ envía a dos de sus discípulos y les dice: vayan a la ciudad, y se toparán con un hombre llevando un cántaro de agua. Siganlo a dondequiera que se meta. Una vez llegados, díganle al dueño de la casa: "el Maestro dice: ¿dónde está la habitación en que voy a comer la Pascua con mis discípulos?". Y él les va a mostrar una sala grande que está en el segundo piso, provista de mesas y bien amueblada, totalmente lista. Alli preparen lo necesario. Y salieron los discipulos y se fueron a la ciudad, y lo hallaron como él les había dicho, y prepararon la Pascua. Y llegado el atardecer, viene con los doce. $Y$ estando recostados a la mesa y comiendo ... tomando un pan, y habiendo pronunciado la bendición, lo partió y se lo dio a ellos, y dijo: tomad este es mi cuerpo. Y habiendo tomado un cáliz y dado gracias, se lo dio, y bebieron de él todos. Y les dijo: esta es mi sangre de la alianza, que es derramada por muchos. En verdad os digo que no beberé ya más del fruto de la vid hasta el día aquel en que lo beba nuevo en el reino de Dios. Y cantados los himnos, salieron al monte de los olivos (Marcos, 14, 12-26).

En efecto, la ley establecía que ello debía tener lugar la tarde del 14 Nisán; al inicio, por tanto, del 15 Nisán primer día de la fiesta de pascua. Según ésto, la muerte de Jesús habría tenido lugar el día siguiente. Sin embargo, según el cuarto evangelio, las cosas habrían sucedido de otra manera totalmente diferente: la muerte de Jesús habría tenido lugar el día en que los hebreos celebraban la cena pascual; es decir, el 14 de Nisán:

Llevan, pues, a Jesús desde Caifás al pretorio. Era el amanecer. $Y$ ellos no entraron en el pretorio para no contraer contaminación que les impidiese comer la Pascua (Juan, 18, 28).

¿Cuál de las dos versiones escoger? ¿Murió Jesús el 15 de Nisán, como sugieren los sinópticos, o el 
14 de Nisán como sugiere el cuarto evangelio? Como es de suponer, hay estudiosos para cada una de las dos opiniones de manera irreconciliable y hay varios intentos de conciliarlas. Por lo demás, dado lo endeble de los datos que poseemos, de la postura que se adopte dependerá que se date un año u otro la muerte de Jesús. La idea de que Jesús fue muerto precisamente el día en que se sacrificaban en el templo los corderos pascuales, que defiende el cuarto evangelio, era una convicción muy arraigada entre los primeros cristianos como lo muestran además textos como la primera carta a los Corintios que dice: "puesto que nuestro cordero pascual que es Cristo fue inmolado" (1 Cor. 5,7). Lo mismo se dice en la primera carta de Pedro que llama a Cristo "cordero sin tacha ni mancilla" (1Pe. 1, 19). Estas y otras razones muy extensas para exponerlas aquí, nos sugieren que es más atendible la cronología del cuarto evangelio y que Jesús murió un viernes (Juan 19,31), 14 de Nisán. Una de estas razones, por ejemplo, es que la amnistía que deja libre a Barrabás y condena a Jesús sólo se aplicaba antes de la noche en que se celebraba la cena pascual; es decir, el 14 de Nisán. Este tipo de puntos de vista muestra las cercanías y lejanías entre Qumrán y el Nuevo Testamento.
6.- En esto y otros casos, la observancia de la ley por parte de Jesús coincide con Qumrán: como por ejemplo su elección de la fecha de la última cena. Mientras que los sinópticos dan a la última cena y a la muerte de Jesús una interpretación, el IV evangelio les da otra. Hoy se sabe que cada una de esas narraciones se atiene a un calendario distinto. En los sinópticos, por ejemplo en Mt 26, 17 - 19 se describe la última cena como una comida de Pascua y Jesús es crucificado al día siguiente. Es porque siguen el calendario lunar que se empleaba en el templo: a este calendario parecen atenerse los sinópticos. En cambio, la comunidad de Qumrán empleaba un calendario solar: a ese se atiene el cuarto evangelio (Joh $12,1$ y 18,28$)$ y habría sido ese calendario el utilizado por Jesús, el de la comunidad de Qumrán. ${ }^{11}$

La comunidad de Qumrán celebraba una fiesta cuyas características rituales eran muy parecidas a las de la última cena descrita por los sinópticos. El texto de Qumrán de la Regla de la comunidad dice: "cuando ha quedado preparada la mesa ... el sacerdote será el primero en extender la mano o bendecir los primeros frutos del pan y del nuevo vino". Y otro texto de la

\footnotetext{
11. M. Delcor / F. García Martínez, Introducción a la literatura esenia de Qumrán, Madrid, Cristiandad, 1982.
} 
Regla mesiánica agrega: "se reunirán en la mesa común, a comer y a beber nuevo vino ... que ningún hombre extienda la mano sobre los primeros frutos del pan y del vino antes que el sacerdote ... luego, el Mesías de Israel extenderá la mano sobre el pan. Así, pues, Jesús debe haber celebrado la última cena según el calendario esenio, la víspera de Pascua. Y a eso se atiene el cuarto evangelio.

7.- Si alguien viera el N. T. desde afuera, lo consideraría como un magno cajón de sastre en el que, según las necesidades y circunstancias, ha sido metido todo y de todo. No sólo subyacen al Nuevo Testamento situaciones y problemas muy distintos que cuadriculan de manera diferente cada uno de los textos que lo conforman sino que, por ello mismo, hay en él obras de muy diferentes géneros literarios: hay un libro de historia (Hech), hay biografías (los evangelios), hay cartas polémicas (Gal.), cartas doctrinales (Rom.) y otros tipos de cartas $\mathrm{y}$ hasta un libro de visiones y revelaciones del más allá (Apoc.). ${ }^{12}$

12. Antonio Piñero / Jesús Peláez, El nuevo testamento. Introducción al estudio de las primeros escritos cristianos, Madrid, El Almendro I Fundación Épsilon, 1995.
8.- No es de extrañar, por eso, que el lector atento detecte en las obras que conforman en el $\mathbf{N}$. T. esas tensiones, contraposiciones, versiones distintas y aún esas contradicciones. Cada obra o, en algunos casos, bloques de obras representan un punto de vista ideológico que se opone frontalmente, $y$ en ese sentido los reflejan, a otros puntos de vista del contexto y Sitz im Leben en que surge y funcionan. Hay muchas otras diferencias entre la imagen de Jesús que ofrecen los tres primeros evangelios y la que ofrece el cuarto evangelio. ${ }^{13}$

9.- El N. T. no representa la ortodoxia fundamental del gran núcleo de cristianos que conforman la Iglesia primitiva. Ambas, ortodoxia fundamental y gran iglesia cristiana primitiva, se irán forjando poco a poco al irse formando el canon del N. T. ${ }^{14}$

10.- El Nuevo Testamento se fue formando primero en forma de tradiciones orales, de tipo comunitario, que se crearon y emplearon para las funciones más importantes de la vida comunitaria. Conforme esas tradiciones arraigaron, sirvieron

13. Antonio Piñero, Guía para entender el Nuevo Testamento, Madrid, Trotta, 2006.

14. Daniel Marguerat (Ed), Introducción al Nuevo Testamento. Su historia, su escritura, su teología, Bilbao, Desclée de Brouwer, 2008. 
más tarde para la redacción de los escritos que hoy conforman el Nuevo Testamento. A eso se refiere la obra de Rudolf Bultmann: La historia de la tradición sinóptica.

11.- Pese a las tensiones, divergencias y contradicciones señaladas, los escritos que conforman el $\mathbf{N}$. $T$. coinciden en al menos tres rasgos. En que sus autores fueron todos judíos del siglo I de nuestra era en plena efervescencia religiosa; en que su entorno sociológico es el Mediterráneo oriental del siglo I en plena efervescencia religiosa; y en que todos los autores escribieron en griego con mayor o menor elegancia.

\section{2.- Si bien el Nuevo Testamen-} to no es una obra de historia, sí contiene los contextos, circunstancias y ambiente vital, que son históricos, lo que le dio origen y en cuyo contexto debe leerse. Dichos contextos, situaciones y circunstancias, concurren con el texto neotestamentario a dar el sentido al conjunto.

13.- Por tanto, el N. T. pertenece por derecho a la historia de la literatura griega. No sólo porque está en griego sino porque es hijo del helenismo y refleja la mentalidad helenística con su retórica y sus concepciones literarias.
14.- Todos los autores del N. T. intentan explicar el mundo y el ser humano en su relación con Dios a través de la fe en una misma persona: Jesús de Nazaret a quien todos interpretan ideológicamente. Puesto que no es un documento histórico, el Nuevo Testamento está cifrado bajo el filtro de la fe de los primeros cristianos. Todas las figuras y estructuras así pergeñadas son fruto de la fe y se contraponen a los productos históricos que se atienen a otros valores y criterios. Es la contraposición entre el Jesús histórico y el Cristo de la fe. ${ }^{15}$

15.- EI N. T. es interpretación de los hechos en clave sobrenatural, es decir, como expresiones de la acción de Dios para salvar al ser humano. Ni una página del N. T. es pura historia. No ofrece hechos comprobables por sí mismos históricamente. Lo que le importa a cada uno de los autores de ese corpus es la interpretación simbólica de esos hechos como expresiones del plan de Dios: la historia de la salvación. ${ }^{16}$

16.- Los hechos fundamentales de la vida de Jesús a la base del N. T. sonarían aproximadamente así:

\footnotetext{
15. Gerd Theissen / Annette Merz, El Jesús historic, Salamanca, Sígueme, 1998.

16. Helmut Köster, Introducción al Nuevo Testamento, Salamanca, Sígueme, 1988.
} 
Un maestro galileo del siglo I, antiguo discípulo de Juan Bautista y que luego funda su propio grupo, atrae a las masas con su proclamación de que el reino de Dios se acerca a toda prisa. Pasó un cierto tiempo predicando esa venida del reino de Dios en Galilea. Mucha gente fue tras él no sólo por su doctrina sino porque era también un sanador y un exorcista, como algúno que otro rabino de la época. Luego subió a Jerusalén a completar su predicación y allí lo prendieron las autoridades porque perturbó el funcionamiento del templo y predijo que Dios lo sustituiría por otro nuevo. Las autoridades lo mataron al considerarlo peligroso para el orden público tanto desde el punto de vista de las autoridades judías como de las romanas.

La interpretación de esos hechos por parte del N. T. es la siguiente en líneas generales: ese maestro de Galilea es en realidad el Hijo de Dios, el mesías tan ansiosamente esperado; según el Cuarto Evangelio, es la Palabra, el Logos de Dios que existe desde siempre y es Dios. Su doctrina es la transmisión de la voluntad divina a los hombres para la salvación de éstos. El Diablo se opone a ese plan de salvación, pero es derrotado en toda la línea por Jesús mismo que demuestra con sus milagros y curaciones que Satanás tiene poco que hacer cuando el reino de Dios impere sobre la tierra. Pero el plan divino incluye el sacrificio del anunciador y mediador de ese reino. Las autoridades terrenales, judias y romanas, impulsadas por el Diablo, lo prenden y lo crucifican. Pero esa aparente victoria es su derrota. En realidad lo que ha pasado es que se ha consumado un sacrificio de la víctima perfecta: un ser a la vez divino y humano que con su muerte ha expiado ante Dios (es Dios) los pecados de los hombres (es hombre). La humanidad queda reconciliada con Dios gracias a este sacrificio único. Pero la víctima no muere definitivamente, sino que resucita. Queda así claro que no es simplemente un hombre, sino un ser que pertenece al ámbito de lo divino. El hombre puede participar de la resurrección de Jesús y apropiarse los beneficios de la salvación si tiene fe en que esos hechos aparentemente banales (la crucifixión por los romanos de un sujeto peligroso ... hecho repetido centenares de veces en Palestina) tienen otro significado. ${ }^{17}$

\section{7.- Hay una notable diferen- cia entre lo realmente acaecido $y$ la interpretación que de ello se ha hecho y nos ha transmitido el $\mathbf{N}$. T. Una diferencia, en suma, entre el Jesús histórico y el Cristo de la fe. El N. T. contiene, en el fondo, la información más antigua sobre los acontecimientos que fundaron}

\footnotetext{
17. Guía para entender el Nuevo Testamento, $O p$ Cit., pp. 24 s.
} 
el cristianismo. Especialmente, los Hechos de los Apóstoles, los evangelios y pasajes de algunas cartas pretenden narrar, de manera fidedigna, hechos realmente acaecidos. Pero, por otra parte, el N. T. es ante todo expresión y testimonio de una fe. Todo lo que cuentan y dicen lo hacen a través del filtro de esa fe y como propaganda de ella. Lo que cuentan los textos neotestamentarios, por tanto, está distorsionado por las lentes de esa fe. Los autores neotestamentarios, pues, son propagandistas de sus creencias. Ello, por tanto, como aconseja la historia de las formas, ha de tenerse en cuenta. ${ }^{18}$

18.- Hoy el Nuevo Testamento que llega a nuestras manos tiene una estructura radicalmente distinta, y en algunos casos hasta opuesta, a como se fue formando. Los veintisiete libros de que consta el Nuevo Testamento se escribieron en un orden totalmente diferente a como hoy los leemos. ${ }^{19} \mathrm{El}$ orden de los escritos neotestamentarios es, en efecto, tardío: procede de los siglos IV y V. De hecho, se escribieron en un orden totalmente diferente y, en algunos casos, totalmente opuesto

18. Sobre este asunto, debe verse el libro de Gerd Theissen y Anette Merz, El Jesús histórico Salamanca, Sígueme, 1999.

19. Para todo esto nos servimos de Antonio Piñero, Guía para entender el Nuevo Testamento, Op. Cit, pp. 29 ss. al que hoy encontramos en las ediciones incluso críticas del Nuevo Testamento. Lo mismo sucedió, por ejemplo, en el interior de cada evangelio entre los relatos de la pasión y el resto del evangelio. ${ }^{20}$

19.- El orden actual es muy conocido $\mathrm{y}$ aparece en las ediciones críticas del Nuevo Testamento como la conocida edición 27 de Nestle Aland $y$ aparece en cualquier edición del $\mathbf{N}$. T: evangelios, hechos, cartas y, al final, el Apocalipsis. Este orden, sin embargo, no refleja el orden real en que los textos fueron escritos. Lo primero que se escribió del Nuevo Testamento son las cartas de Pablo de Tarso personaje principal que ya aparece en el libro de Hechos de los Apóstoles. De hecho, el primer escrito neotestamentario es la 1 Tesalonicenses, escrita hacia el año 51. Contra el orden en que se leen y las creencias de algunas tradiciones, el primer evangelio que se escribió no fue el de Mateo sino el de Marcos, que fue compuesto hacia el año $70 /$ 71. En su forma original, el evangelio de Marcos llegaba hasta Mc 16, 8. En el siglo II se añadieron los vv 9 - 20. El último evangelio que se escribió fue el de Juan, el cuarto evangelio, compuesto entre los años 90 y 100 . Son muchas las

20. Ibid. 
consecuencias hermenéuticas que se desprenden del orden habitual: el lector tiene otra impresión de lo que es el N. T. ${ }^{21}$

20.- El Nuevo Testamento, tal cual hoy circula, pone en primer lugar el evangelio de Mateo porque, según tradiciones antiguas, se creía que era el más antiguo. Hoy sabemos que el primer evangelio que se escribió fue el evangelio de Marcos. Por tanto, en una edición que colocara los evangelios por orden de antigüedad, el primero que debería ir sería el de Marcos. ${ }^{22}$

21.- El actual orden neotestamentario separa partes de obras que en sus orígenes conformaban una sola obra: el evangelio de Lucas y Hechos de los Apóstoles. Escritas como una sola obra, estas dos partes fueron separadas por el simple hecho de que por su tamaño no cabían en un solo rollo normal de papiro. Luego, la separación se vio que no era descabellada: el evangelio tenía la estructura, formato y contenidos de los otros dos evangelios, y trataba la acción del Espíritu Santo en Jesús en el centro del tiempo. En tanto

21. Senén Vidal, El primer escrito cristiano, Salamanca, Sígueme, 2006.

22. Antonio Piñero (Ed.), Fuentes del cristianismo, Córdoba / Madrid, El Almendro/ Universidad Complutense, 1993. que Hechos, desarrollaba la obra del Espíritu Santo en los seguidores de Jesús, sus discípulos. Hechos tiene como protagonista a Pedro en los primeros 12 capítulos y a Pablo, en los 14 últimos. Sin embargo, la doble obra de Lucas es, en realidad, una sola obra en dos partes que se complementan entre sí y cada una requiere de la otra para su comprensión. ${ }^{23}$

22.- En el actual formato del Nuevo Testamento aparecen separadas cuatro obras pertenecientes al grupo o escuela de Juan: el cuarto evangelio y las tres epístolas johánicas. Hoy se sabe que estas obras no fueron compuestas por un mismo autor aunque sus autores pertenezcan al mismo grupo teológico. El actual orden de esos escritos no ayuda al actual lector a su lectura y comprensión. El cuarto evangelio fue el último de los cuatro evangelios que se escribió: su redacción data en torno al año 100 aunque una serie de términos revelan su contacto con tradiciones antiguas independientes de los sinópticos.

23.- El llamado corpus paulino tampoco aparece en el orden cronológico de su composición en nuestras actuales ediciones del $\mathbf{N}$. T. La carta a los Romanos, la primera que

23. Véase Guía para entender el Nuevo Testamento, Op. Cit., p. 30. 
aparece en nuestras ediciones, es cronológicamente la última. Para entender mejor el pensamiento de Pablo habría que leerlo atendiendo el orden original de su composición: Pablo va progresando en su pensamiento. La disposición actual obedece solamente al tamaño de las cartas: de mayor a menor según tres bloques: Rom., 1 Cor., 2 Cor., Gal. / Ef., Flp., Col., 1 Tes., 2 Tes. / 1 Tim., 2 Tim., Tt., Flm. Como ya hemos dicho, no está la Epístola a los Hebreos: es un sermón y no es paulino.

24.- Las epístolas católicas se llaman así porque no van dirigidas a ninguna comunidad en particular sino a todas las iglesias. Orígenes aplicó este nombre a 1 Pet, a 1 Joh y a Jds. Luego Eusebio y San Jerónimo extendieron el título a las siete epístolas que hoy se conocen con ese nombre: Carta de Santiago, 1 y 2 Pedro; 1, 2 y 3 de Juan y Carta de Judas.

\footnotetext{
25.- En los albores del cristianismo, no existía el Nuevo Testamento porque no era necesaria una nueva colección de libros sagrados y por otras razones. El primer nombre que se dio a los primeros cristianos fue el de "nazarenos" (Hech 24, 5): a Pablo lo acusan en Cesarea de ser jefe de la secta de los "nazarenos"). El grupo se extendió en Palestina. Fue en Antioquia de Siria donde se
}

empezó a llamar a los primeros creyentes en Jesús de Nazaret, "cristianos" por lo de Cristo o Mesías. Eran llamados también "mesianistas". Eran tenidos como un grupo o secta judía. No tenían, por tanto, al principio, una Biblia propia: sus escrituras eran las mismas de cualquier grupo Judío. Además, no necesitaban más escrituras. No tenían escrituras porque, en primer lugar, Jesús no escribió nada ni mandó a sus discípulos que escribieran libros para conservar sus palabras. Además, los primeros cristianos no pensaban que estuvieran formando una nueva religión. Pablo, por ejemplo, había dejado claro en su Carta a los Romanos que los nuevos creyentes eran sólo un injerto del olivo antiguo de la religión judía.: como los miembros de la comunidad de Qumrán, los primeros creyentes se consideraban "el verdadero Israel" que, por tanto, perfeccionaban la vieja religión. Ellos y los de Qumrán pensaban que los judíos habían abandonado la alianza con Dios puesto que rechazaban al Mesías. Y si, pues, los cristianos eran el verdadero Israel no necesitaban nuevas escrituras: con las que tenían les bastaba. Sólo había que interpretarlas correctamente para que se pudiera reconocer a Jesús como el verdadero Mesías. Lo que hoy llamamos Antiguo Testamento era, por eso, la Biblia de 
los primeros cristianos: la de los nazarenos / cristianos. ${ }^{24}$

26.- Sin embargo, poco a poco, en el seno de los diferentes grupos, se fueron generando escritos para uso interno. $Y$ empezaron a escribir en papiros, pergaminos y códices los dichos de Jesús, sus sentencias, sus milagros y tal vez hasta especies de florilegios con textos de la Escritura que probaban que Jesús de Nazaret era el Mesías. Al ritmo de la vida, además, se fueron creando textos portadores de las reflexiones que se hacían los nuevos creyentes sobre sus diferencias con la vieja religión de los judíos, exponiendo sus propias convicciones religiosas sobre todo en torno a la persona de Jesús. Sólo muchas, muchas, décadas después, estos escritos de circulación interna, especie de vademecum o prontuarios para cristianos no judíos, que daban cuerpo a las convicciones que se iban formando en las diferentes comunidades, empezaron a ser considerados como dotados de autoridad, como "sagrados". Ello habrá sucedido cuando la secta de los nazarenos se separó definitivamente del judaísmo. Esto tendría lugar hacia el año 80 cuando, tras la destrucción del templo de Jerusalén por los ejércitos

24. Véase Guía para entender el Nuevo Testamento, Op. Cit., p.38. romanos, tiene lugar la fundación de la Academia de Yamnia con la que nace el judaísmo moderno. ${ }^{25}$

27.- Los primeros escritos que más tarde habrían de formar parte del Nuevo Testamento fueron cartas: no fueron los evangelios. Ya hemos señalado que son las cartas los primeros escritos que circulan entre los miembros de la nueva religión para confirmarse en la fe o para responder a las dudas, preguntas y problemas que se planteaban los primeros creyentes. Necesitaban, muchos de ellos, noticias sobre la persona y doctrina del maestro. Con las cartas, pues, se resolvían los problemas más urgentes que van planteando a sus dirigentes los primeros miembros de la nueva religión. Como hemos dicho, de las cartas que se escribieron al principio de la nueva secta se han conservado siete que llevan la firma de un personaje histórico: Pablo de Tarso que fue un activo fundador de iglesias que andaba de comunidad en comunidad: fue, pues, una especie de misionero itinerante o agente viajero de la nueva religión que, como tal, al abandonar las comunidades recién fundadas debía responder a una serie de dudas y cuestiones que le planteaban los

25. Jean Louis Ska, Cosas nuevas y viejas (Mt 13, 52. Páginas escogidas del evangelio de Mateo, Estella, 2004, pp. 8 y ss). 
nuevos fieles. Algunas de estas cartas misioneras serán incluidas más tarde en el N. T. La 1 Tes es el primer escrito cristiano escrita hacia el año 49. No todas, desde luego, y debido a ese carácter de escritos ocasionales no era de esperar que tuvieran el carácter de tratados sistemáticos de la nueva fe: sólo respuestas y soluciones a problemas y casos concretos. ${ }^{26}$

28.- Cuando murieron Pablo y los primeros misioneros, la costumbre de comunicarse a través de cartas siguió entre los nuevos dirigentes, sus discípulos, y las respectivas comunidades que, por supuesto, seguían teniendo las mismas o análogas necesidades de comunicación. $\mathrm{Y}$ los nuevos dirigentes siguieron utilizando cartas para instruir a sus fieles de los nuevos problemas. Sólo que la gran mayoría de esos nuevos dirigentes no se animaron a firmar con su nombre sus propias cartas: recurrieron para ello al apoyo de la autoridad del maestro fallecido: Pablo, Pedro, Santiago, Juan, Judas fueron los nombres a quienes se atribuyó la emergente literatura epistolar huérfana de autor. Hoy sabemos, en efecto, que los escritos neotestamentarios que a esos autores se atribuyen no fueron escritos

26. cfr. Senén Vidal, El primer escrito cristiano, Salamanca, Sígueme, 2006. por ellos sino por seguidores suyos. A este hecho se le conoce como pseudonimia. Hoy se llamaría a eso falsificación: era un recurso muy usado en la antigüedad: discípulos de Orfeo, Pitágoras, Hipócrates y Platón, por ejemplo, emplearon el nombre de su maestro para garantizar la vida a sus escritos. Las cartas de la segunda generación (Ef., Col., 2 Tes.) y de la tercera generación (Hebreos, Pastorales, Santiago, 1 y 2 Pe., Jds.) se caracterizan además porque tratan problemas más generales: ya no problemas inmediatos. Por ejemplo: por qué se retrasa el fin del mundo, cómo hay que organizar la iglesia en ese tiempo de espera, cómo hay que constituir los cargos eclesiásticos, cuáles son las verdades que hay que creer y cuáles no; qué pasa con los cristianos si ya no existen ni Jerusalén ni el templo; cuál debe ser el lugar de las mujeres en la Iglesia; cuál el lugar de los jóvenes y de los ancianos en una comunidad bien constituida. ${ }^{27}$

29.- A medida que las iglesias cristianas tenían que ubicarse en el mundo puesto que se retrasaba la parusía, se empezaron a generar naturalmente escritos de otra índole, y no sólo cartas. Como se iban muriendo los que habían conocido

27. Julio Trebolle Barrera, La Biblia judía y la Biblia cristiana, Madrid, Trotta, 1998. 
a Jesús, los predicadores y catequistas necesitaban tener reunidos dichos y hechos del maestro para ir armando su proclamación esencial, la buena noticia: la salvación de la humanidad entera por la muerte en cruz del mesías. Se fueron formando así pliegos o breves notas sobre Jesús, pequeñas colecciones de dichos, o de milagros, la historia de la pasión. Esta recopilación de material biográfico habría tenido lugar hacia los años 50. El primer evangelio, como tal, el de Marcos, se habría compuesto unos veinte años después del año 70. Esta manera de conservar las cosas relativas a Jesús, primero, y luego de seleccionarlas según los intereses y necesidades de las comunidades, aparte de los intereses particulares de los coleccionistas hicieran que, en general, no se perdiera nada importante de cuanto circulaba por tradición oral entre las comunidades. ${ }^{28}$

30.- Hubo dos elementos que hicieron no sólo necesario sino urgente el surgimiento de la literatura evangélica. Primero, el ingreso de paganos al cristianismo: seguidores de Jesús que no lo habían conocido personalmente y que, por lo demás, necesitaban algún tipo de instrucción para comprender las

28. John S Kloppenborg, Q el evangelio desconocido, Salamanca, Sígueme, 2005. costumbres y teología judías. En segundo lugar, había que contrabalancear el cristianismo primitivo en el que era mucha la preponderancia paulina cuya doctrina resultaba abstracta y descarnada. Se necesitaba algo más vivencial. Los primeros relatos $\mathrm{y}$, de hecho, los más recientes, eran los de la muerte y la resurrección. Por allí empezaron a formarse los evangelios: el resto era su vida, dichos y hechos del maestro.

31.- Después de Marcos, se escribieron otros evangelios, "muchos", dice Lucas en su prólogo. Esos otros evangelios reflejaban, claro está, perspectivas distintas: escuelas, ideologías, comunidades y problemas. Del cúmulo de evangelios que se escribieron, la comunidad primitiva, mediante los procesos que serán expuestos a propósito del "canon", escogió cuatro. Hoy se les conoce como evangelios de Mateo, Marcos, Lucas y Juan. Estos cuatro evangelios eran muy probablemente anónimos: cada uno de ellos fue compuesto por un miembro destacado de un grupo cristiano importante.

32.- Los evangelios tienen a la base tradiciones populares nacidas $\mathbf{y}$ desarrolladas en torno al acontecimiento de Jesús de Nazaret y, como todas las tradiciones populares, tampoco los evangelios reconocen 
un autor individual. Estas tradiciones relacionaron, más tarde, el origen de los evangelios a autores individuales de los que no sabemos prácticamente nada. Si acaso el nombre. Es muy difícil, por lo que se puede deducir entre líneas, que los autores a quienes se atribuyen los cuatro evangelios hayan sido del grupo inmediato de discípulos inmediatos del maestro: los cuatro evangelios fueron escritos después del año 80, cincuenta años después del Concilio de Jamnia. Parece ser, más bien, que los evangelistas eran seguidores de algunos de estos discípulos: se trataba, pues, de cristianos de la segunda y aún tercera generación. Las atribuciones a los autores, pues, son erróneas. De lo que parece tratarse es dejar en claro que la tradición sobre Jesús se basaba en lo transmitido por testigos visuales. Sin embargo, cada autor armó su evangelio según una idea teológica distinta. ${ }^{29}$

33.- Todos los evangelios reflejan las huellas de la situación posterior al año 70. El evangelio de Marcos recoge el sitio y destrucción de Jerusalén a manos de los ejérci-

29. Rafael Aguirre Monasterio / Antonio Rodríguez Carmona, Evangelios sinópticos y Hechos de los apóstoles, Estella, Verbo divino, 1992. tos romanos en el capítulo 13, en el llamado "discurso escatológico". ${ }^{30}$

34.- El marco histórico del evangelio de Mateo fue la destrucción de Jerusalén y la Academia de Yamnia. El evangelio de Mateo fue estructurado sobre muchas huellas de la nueva situación tras la destrucción del templo en donde la máxima autoridad; la vieja ley, resulta contrapuesta a la nueva ley por ejemplo en el sermón de la montaña. En la "parábola del banquete nupcial" el evangelista contrapone a los nuevos cristianos con los cristianos de origen judío: "se enojó el rey y, enviando sus tropas, dio muerte a aquellos homicidas y prendió fuego a su ciudad". (Mt. 22, 7), obvia alusión a la destrucción de Jerusalén e indicación segura sobre la datación del evangelio hacia el año 80,85 . Jesús aparece en el evangelio de Mateo no sólo como el Mesías en quien se cumplen las profecías antiguas, sino un nuevo Moisés que propone una nueva ley y funda una nueva comunidad eclesial. El reino de Dios les será quitado a los judíos para ser entregado a otra nación: es el evangelio de los paganos: $\mathrm{Mt}$ 21, 43: "por eso os digo que se os quitará a vosotros el Reino de los Cielos y se entregará a un pueblo que dé sus frutos".

\footnotetext{
30. Felipe F. Ramos, El nuevo Testamento I Presentación y contenido, Madrid, Sociedad de Educación Atenas, 1988.
} 
35.- A raíz de la ruptura de los cristianos con el judaísmo tradicional, tras la destrucción del templo, en el año 70, el evangelio de Mateo sistemáticamente trata de demostrar que en Jesús de Nazaret se cumplen todas las profecías del Antiguo Testamento: que un nuevo orden ha sido inaugurado con una nueva ley que conforma un nuevo pueblo, en sustitución del antiguo orden. Es constante la frase: "esto sucedió para que se cumpliera lo dicho por el profeta..."

36.- El evangelio de Marcos es el primero que fue escrito. No se sabe quién fue "Marcos", ni cuándo se escribió el evangelio. El punto de referencia para la fecha de composición es la destrucción de Jerusalén a la que hace alusión en Mc 13. Eso fue después del año 70 cuando ya habían madurado simbólicamente los acontecimientos de la destrucción del templo.. Este evangelio fue escrito probablemente entre el año 75 y $80 .{ }^{31}$

37.- Los 3 evangelios sinópticos muestran huellas de una etapa escrita posterior a la conformación

31. Sobre la antigüedad de Marcos y la cueva 7 de Qumran, véanse los trabajos de Joseph O'Callaghan y la recepción de la crítica, véase Graham Stanton, ¿La verdad del evangelio? Nueva Luz sobre Jesús y los evangelios, Villatuerta, 1999. de tradiciones orales, hacia el año 70, y anterior a la redacción de los textos cual llegaron a nosotros bajo la forma de "evangelio". Una de las recopilaciones funcionales de dichos es la conocida como Documento $Q$ que concurre con Marcos y otras colecciones a la formación de Mateo y Lucas. ${ }^{32}$

38.- El cuarto evangelio, Juan, es el más tardío de los cuatro evangelios. Es una historia desde las alturas: la gesta, a saber, de la palabra que desde el principio estaba junto a Dios, cuando creó el mundo y que, desde allí, bajó a los suyos, pero los suyos no le recibieron. A los que le recibieron les dio el poder de convertirse en hijos de Dios. El cuarto evangelio ha solido atribuirse a Juan, uno de los hijos del Zebedeo, pescador de Galilea. Hay muchísimos indicios de que eso no es así. ${ }^{33}$ No se sabe quién era "el discípulo que Jesús amaba". En todo caso, este evangelio se escribió entre el 125 y el 130, aunque haya en él rastros de aramaísmos que delata un sustrato arcaizante. Tiene las huellas del gnosticismo galopante en el siglo II. ${ }^{34}$ En efecto, en

32. Cfr James M Robinson / Paul Hoffmann / John Kloppenborg, El Documento Q, Salamanca, Ed. Sígueme/ Peeters Leuven, 2002.

33. Cfr. Jean Colson, L'enigme du disciple que Jesús aimait, París, Beuchesne et ses fils, 1968.

34. Véase Pablo Richard, Memoria del "movimiento histórico de Jesús” desde sus orígenes 
la segunda mitad del siglo II se da una abundante eclosión de evangelios gnósticos. ${ }^{35}$

39.- Mateo y Lucas tuvieron la obra de Marcos ante sus ojos al escribir sus evangelios y además copiaron de otra fuente, es decir, de otro "evangelio", cuyo contenido consistía fundamentalmente en dichos y sentencias de Jesús conocido como Documento Q. Marcos influye en Mateo y en Lucas. La fuente Q influye también en Mateo y en Lucas. Esta es la teoría llamada de las dos fuentes. Cada uno de los otros dos sinópticos habrían sido influidos por Marcos y el evangelio perdido Q. Pero no sólo eso: hay unos pasajes que son propios de solo Mateo y pasajes que sólo Lucas trae. Pocos. Estos pasajes propios de Mt o Lc no se encuentran en Mc. Probablemente vienen de tradiciones orales a que tuvieron por separado acceso cada uno de los evangelistas. Existían, pues, tres estratos de material evangélico antes de que se compusieran Mt. y Lc.: Mc., Q., SMt. y SL. Hoy se conoce y ha sido publicado el evangelio perdido mencionado aquí como Q. ${ }^{36}$

(años 30) hasta la crisis del Sacro Imperio Romano Cristiano ()

35. Véase Armand Puig (editor), Los evangelios apócrifos, Madrid, Ariel, 2008, p.23.

36. Jhon S. Kloppenborg, El evangelio desconocido, Salamanca, Sígueme, 2005.
40.- El Nuevo Testamento está escrito en términos mitológicos de la época en que se escribió y hay que desmitologizarlo para que se conserve su sentido y pueda ser leído y comprendido por el lector contemporáneo. Según el historiador y exégeta Rudolf Bultmann, tras señalar que el Nuevo Testamento está cifrado en lenguaje del mito, es necesario un amplio programa de desmitologización del Nuevo Testamento. ${ }^{37}$

El mundo es visto allí como una estructura de tres pisos con la tierra en el centro, los cielos arriba y el indigno inframundo. Los cielos son la morada de Dios y de los seres celestes, los ángeles. El inframundo es el infierno, el lugar de tormento. Además, la tierra es algo más que el escenario de lo natural, de los eventos cotidianos, de la esfera trivial y del deber común y corriente: la tierra es el escenario de la actividad superior de Dios y su ángeles, por una parte, y de Satán y sus demonios por otra. Esas fuerzas sobrenaturales intervienen en el curso natural de las cosas y en todo lo que el hombre piensa, quiere y hace. Los milagros no son de ninguna manera raros. El hombre no

\footnotetext{
37. Cfr. Rudolf Bultmann, Jesus Christus und die Mythologie, Hamburg, Furche-Verlag, 1964, y Jésus. Mythologie et démythologisation, Paris, Ed. de Seuil, 1968.
} 
tiene el control de su propia vida. Espíritus infernales pueden tomar posesión de él. Satán puede inspirarle pensamientos infernales. De la otra parte, Dios también puede inspirarle su propio pensamiento y guiar sus actos; puede además concederle visiones celestiales, escuchar sus peticiones de auxilio y sus peticiones, y otorgarle el poder sobrenatural de su Espíritu. La historia no sigue un curso plano e intacto: su curso está colocado bajo la moción y controlado por esos poderes sobrenaturales. Este eón (mundo) es mantenido en cautiverio por los respectivos poderes de Satán, el pecado y la muerte, y se aproxima a su fin. Este fin vendrá muy pronto y tomará la forma de una catástrofe cósmica: será inaugurada por las aflicciones de los últimos tiempos. Entonces vendrá el juez de los cielos, se levantarán los muertos, y tendrá lugar el último juicio y los hombres entrarán ya en la salvación eterna, ya en la condenación eterna. Este es el panorama mítico que el Nuevo Testamento propone cuando presenta el acontecimiento de la redención, objeto de la predicación: proclama en el lenguaje de la mitología que los últimos tiempos han llegado ya. "En la plenitud de los tiempos" Dios envió a su Hijo, un ser divino preexistente, que se presenta en la tierra bajo la apariencia de hombre. Él murió en la cruz la muerte de los pecadores en expiación por los pecados de los hombres. Su resurrección marca el comienzo de la catástrofe cósmica. La muerte, consecuencia del pecado de Adán, ha sido abolida y las fuerzas del demonio han sido privadas de sus poderes. Cristo resucitado ha sido entronizado a la derecha de Dios en los cielos como "Señor" y "Rey". Él vendrá de nuevo de entre las nubes del cielo a completar la obra de redención, y tendrán lugar entonces la resurrección y juicio de los hombres. El pecado, el sufrimiento y la muerte serán finalmente abolidos. Todo ello es esperado para muy pronto; tanto que San Pablo piensa que él mismo aún vivirá para ver todo eso. ${ }^{38}$

41.- Qumrán no es sólo el nombre de un importante sitio arqueológico, sino de un asentamiento importante de tiempos del Nuevo Testamento y, desde luego, de una importantísima y vasta biblioteca de la época de un grupo judío. El descubrimiento, traducción, estudio y publicación de los textos allí encontrados, nos ha hecho comprender mucho mejor la naturaleza, orígenes e índole del cristianismo y desde luego del Nuevo Testamento

38. "New Testament and Mythology", Op. cit., pp. 1 y s. 
y de la índole de los grupos que concurrieron para conformarlo. ${ }^{39}$

42.- Al contrario de lo que se pensaba y se quería aceptar, hay muchos puntos de contacto entre Qumrán, el Nuevo Testamento y los orígenes del cristianismo cuya originalidad debe ser relativizada. Hoy prevalece la convicción, por ejemplo, de que los moradores de las ruinas del mar Muerto, según los datos arrojados por la arqueología y según la crítica interna de una serie de documentos de los llamados "sectarios" por los investigadores, eran "celotas" ("celosos de la ley"), fanáticos exaltados que luchaban, por ese motivo, contra los invasores romanos. Hay, por ello, numerosos puntos de los textos encontrados en Qumrán que tienen paralelos con los textos cristianos primitivos. ${ }^{40}$

43.- Hay mucha semejanza entre el ritual del bautismo cristiano y el ritual de ingreso a la comunidad de Qumrán. Según "La regla de la comunidad", el nuevo miembro de la comunidad "será limpiado de

39. Entre la abundante bibliografía sobre el Mar Muerto, puede verse James Vanderkam y Peter Flint, El significado de los rollos del Mar Muerto, Madrid, Trotta, 2008.

40. Para esto, me valgo del libro de Michael Baigent / Richard Leigh, La conspiración del Mar muerto, Madrid, Mr. Ediciones,2006, pp. $193 \mathrm{ss}$. todos sus pecados por el espíritu de santidad que lo unirá a su verdad ... Y cuando su carne sea rociada con agua purificadora y santificada con agua limpiadora, quedará limpia por la humilde sumisión de su alma a todos los preceptos de Dios.

44.- Según Hechos de los Apóstoles $(2,44$ - 46), los miembros de la Iglesia Primitiva lo compartían todo: "todos los creyentes vivían unidos y tenían todo en común, vendían sus posesiones y sus bienes y repartían el precio entre todos, según la necesidad de cada uno. Acudían al templo todos los días con perseverancia y con un mismo espíritu..." Cosa parecida dice el primer estatuto de la Regla de la comunidad de Qumrán:: “todos traerán todo su conocimiento, sus fuerzas y sus posesiones a la Comunidad. Según otro de los estatutos de la Regla, "Comerán juntos y rezarán juntos..." Otro, en fin, dice del recién ingresado que su propiedad será integrada y él ofrecerá su consejo y su juicio a la Comunidad..." Hech 5, 1 - 11, cuenta la historia de Ananías y su mujer quienes pretenden hacer como que venden su propiedad para dar su fruto a la comunidad pero se quedan con el fruto de la venta. Caen muertos como castigo. En Qumrán, el castigo por ese tipo de fraude consistía, según la Regla, en seis meses de penitencia. 
45.- Según Hechos, la dirección de la Iglesia Primitiva de Jerusalén consta de doce apóstoles. Pero Santiago ("el hermano del Señor"), Juan y Pedro ejercen una especial autoridad. Por su parte, según la Regla de la comunidad, Qumrán debía estar gobernada por un consejo compuesto por doce personas y también destaca a tres sacerdotes.

46.- Tanto la comunidad de Qumrán como la iglesia primitiva tenían una orientación específicamente mesiánica dominada por el inminente advenimiento de un nuevo mesías. Coincidían ambas en postular una intensa y carismática figura central, cuya personalidad los vivificaba y cuyas enseñanzas formaban los cimientos de sus creencias. Jesús, para la Iglesia primitiva; el Maestro de Justicia para los miembros de la comunidad de Qumrán. De tal manera se parecen ambos personajes que, muchas veces, cuando en los documentos de Qumrán se habla del Maestro de Justicia, parece como si se estuviera refiriendo a Jesús. El Maestro de Justicia no es un ser divino: a Jesús sólo se lo representó así en los textos más tardíos: es decir, pasado algún tiempo.

47.- Si los textos de Qumrán y los de la Iglesia primitiva tienen algunas ideas, conceptos y principios en común también se parecen mucho en la fraseología y en las imágenes. ${ }^{41}$ Por ejemplo en el sermón de la montaña, en Mt. 5, 4, se dice: "bienaventurados los mansos, porque ellos poseerán la tierra": Eso procede del salmo 37, 11 que interesaba especialmente a la Comunidad de Qumrán que habla de la Congregación de los Pobres y que era uno de los nombres con que los miembros de esa comunidad se designaban a sí mismos. Si la bienaventuranza "bienaventurados los pobres de espíritu porque de ellos es el Reino de los Cielos (Mt. 5, 3), el Rollo de la guerra de la Cueva 1 dice: "entre los pobres de espíritu hay un poder...". Los capítulos 10 y 18 de Mt contienen metáforas y terminología a veces casi intercambiables con las de la "Regla de la Comunidad". Por ejemplo, en Mt. 5, 48 se dice "sed perfectos como vuestro Padre Celestial es perfecto", la "Regla de la Comunidad" habla de "los que caminan por el sendero de la perfección como si los mandara Dios". En Mt. 21, 42 citando Os 28, 16 tanto como el salmo 118, 22 se dice: "la piedra que desecharon los constructores vino a ser la piedra angular", la "Regla de la Comunidad" se refiere

\footnotetext{
41. Véase Florentino García Martínez / Julio Trebolle Barrera, Los hombres de Qumrán. Literatura, y estructura social y concepciones religiosas, Madrid, Trotta, 1993.
} 
a lo mismo cuando, refiriéndose al Consejo de la Comunidad, dice "será esa probada pared, esa preciosa piedra angular".

48.- Si los rollos de Qumrán tienen tantas analogías con los evangelios que se hacen ecos unos a otros, esas estrechas similitudes aumentan si comparamos los rollos con los textos paulinos: en concreto, Hechos de los Apóstoles y epístolas de Pablo. ${ }^{42}$ Empecemos por el concepto de "santidad" que subyace, desde luego, a la palabra "santo" tan comunes en el cristianismo tardío pero que, en los rollos del Mar Muerto, son sorprendentes. El comienzo, precisamente, de la Regla de la comunidad dice que "el Maestro enseñará a los santos a vivir de acuerdo con el Libro de la Comunidad..." Y, por su parte, Pablo (en Rom. 15, 25 - 27) usa la misma terminología de la Iglesia Primitiva: "mas ahora voy a Jerusalén a ministrar a los santos".

49.- Pablo utiliza con profusión los términos y las imágenes de Qumrán. Por ejemplo: uno de los textos de Qumrán habla de "todos aquellos que observan la ley en la Casa de Judá, a quienes Dios

42. Véase Florentino García Martínez (Editor y traductor), Textos de Qumrán, Madrid, Trotta, 1992. librará ... a causa de sus padecimientos y a causa de su fe en el Maestro de Justicia”. Pablo, como ya hemos señalado, atribuye un poder redentor similar a la fe en Jesús. Por ejemplo, en Rom. 3, 21 23 dice que la justicia de Dios llega "por la fe en Jesucristo". Y en Gal. 2, 16 - 17 declara que "el hombre no es justificado por las obras de la ley, sino por la fe en Jesucristo". Vemos, por tanto, que Pablo está familiarizado con las metáforas, los giros, la retórica utilizada en la Comunidad de Qumrán, en su interpretación de los textos del A. T.

50.- Sin embargo, para Pablo la ley no tiene un significado absoluto. En el apenas citado texto de Gal. 2, 16 - 17 declara que "el hombre no es justificado por las obras de la ley, sino por la fe en Jesucristo", Pablo no atribuye un significado desmedido a la ley. En los textos de Qumrán, en cambio, sí se atribuye a la ley una gran importancia. Por ejemplo, en La regla de la comuni$\mathrm{dad}$, se dice, al principio: "el Maestro enseñará a los santos a vivir de acuerdo con el libro de La regla de la comunidad, para que pueda buscar a Dios ... y hacer ante él lo que es bueno y justo, como él ordenó mediante Moisés y todos sus servidores los profetas..." Más adelante, la Regla de la comunidad establece que todo el que "transgreda una palabra de la Ley de Moisés, 
o cualquier otro punto, será expulsado" y que "la ley durará mientras dure el dominio de Satanás". Por consiguiente, se ve que Jesús, en su rigurosa observancia de la ley, está mucho más cerca de Qumrán que Pablo. En el Sermón de la Montaña (Mt, 5, 17 - 19), Jesús nos deja muy clara su posición a este respecto y que, como hemos visto está muy cercana a Qumrán:

No penséis que he venido a abolir la Ley y los Profetas. No he venido a abolir, sino a dar cumplimiento. Sí, os lo aseguro: el cielo y la tierra pasarán antes de que pase una $\mathbf{i} o$ una tilde de la Ley sin que todo se cumpla. Por lo tanto, el que se salte uno de estos mandamientos más pequeños y así lo enseñe a los hombres, será el más pequeño en Reino de los Cielos.

\section{El canon del \\ Nuevo Testamento}

El canon del Nuevo Testamento se fue formando lentamente al ritmo de la vida a lo largo de los dos primeros siglos cristianos. ${ }^{43}$ Como ya se sabe, Jesús no escribió nada. Algunos de sus seguidores sí. Sin embargo, del cúmulo de escritos que en este contexto surgen y circulan no todos tuvieron la misma

43. Cfr. F. Bruce, El canon de la escritura, Barcelona, Villadecavalls, 2002. autoridad y prestigio: eso lo fueron adquiriendo los textos a lo largo de varios y complejos procesos de selección que se extendieron hasta finales del siglo II. En efecto, sólo a finales del siglo II, cuando el canon ya estaba prácticamente formado, aparecen los primeros textos claramente normativos sobre cuáles de los escritos que estaban en uso entre las comunidades cristianas deban tenerse como obligantes. A fines del siglo I y durante el siglo II sólo encontramos indicios de cómo se fue dando este importante proceso. Por tanto, no conocemos a ciencia cierta cómo fueron estos procesos de formación de lo que sería llamado el "canon". La historia que de esos procesos aquí presentamos tiene sólo un valor hipotético. La palabra "canon", como se llama en griego a la caña de medir, es, por extensión, la norma o regla que dice qué libros deben ser tenidos como sagrados. Se llama, en efecto, "canon neotestamentario" a la lista de libros aceptados como sagrados por los diversos grupos cristianos. A tales libros se les llama, por ese motivo, "libros canónicos".

Empero, el empleo de las palabras canon, canónico o canonizar, referido al conjunto de escritos cristianos sagrados, es bastante tardío: se remonta al siglo III. Los primeros cristianos sabían lo que tenían que hacer a partir de las siguientes autoridades: 
1. Las escrituras judías. Como dijimos arriba, el nuevo grupo judeocristiano aceptó, sin más, los libros de lo que hoy llamamos el "Antiguo Testamento".

2. La segunda autoridad con ascendiente entre los primeros cristianos fue la tradición sobre las palabras del señor. Las tradiciones sobre las palabras del señor, de esta manera, tenían valor de norma. En la iglesia primitiva, por tanto, reunieron colecciones con las palabras de Jesús y que las citara al lado de "la ley y los profetas" atribuyéndoles la misma autoridad.

3. La tercera autoridad que acataban los primeros cristianos fue, primero, la de los apóstoles y, después, la de los maestros cristianos.

4. La cuarta autoridad era el "espíritu de Jesús" al cuidado de algunas sinagogas a cargo de maestros y apóstoles itinerantes y, sobre todo, de profetas.

Entre finales del siglo II y comienzos del III, como hemos dicho, aparecen de repente entre los cristianos las menciones de una nueva lista de escritos sagrados: curiosamente esta lista está ya casi bien formada. Los primeros testigos del canon cristiano son:

1. El Fragmento de Muratori. En Roma, hacia el año 200 el canon o fragmento muratoriano dice que a principios del siglo III eran ya canónicos los cuatro evangelios (Mt., Mc., Lc., Jn.); los Hechos de los Apóstoles; 13 epístolas de San Pablo (falta hebreos); dos epístolas de Juan y una de Judas; dos Apocalipsis: el de Juan y el de Pedro. En total, en el Canon muratoriano aparecen 23 de los 27 escritos que hoy forman el N. T. De ellos, faltan las 1,2 Pe., Sant. y Heb. Desde luego, de esta lista sobra el Apocalipsis de Pedro y el Libro de la sabiduría que aparece mencionado como libro del N. T.

El erudito italiano, L. A. Muratori $(1672$ - 1750) descubrió en la Biblioteca Ambrosiana de Milán un manuscrito del siglo VIII, probablemente proveniente de la abadía benedictina de Bobbio. El manuscrito contenía la lista de libros que debían ser tenidos como canónicos. Por eso se le conoce también como "Canon de Muratori”. En el siglo XX (1987) se descubrieron otros cuatro fragmentos. Parece remontarse el conjunto al año 200 y tiene la apariencia de una traducción latina torpe, de un original griego, no sabemos si privado u oficial, pero en todo caso tiene toda la intención de ser un escrito normativo. Hay enumerados 23 de los 27 libros del Nuevo 
Testamento: faltan Hebreos, Santiago, 1-2 Pedro y 3 de Juan. ${ }^{44}$

2. Ireneo de Lyon, en su obra $A d$ versus hereses, escrita hacia el año 180 , dice que son tenidos como canónicos los 4 evangelios, 12 epístolas de Pablo (falta Flm. y hebreos) y 1 Pe., 1 y 2 Jn., Sant. y Apoc. Faltan 2 Pe., 3 Jn. y Jds. Tertuliano, en el N. de África, hacia el 200, cita todos los escritos que hoy constituyen el N. T. excepto 2 Pe., Snt., 2 y 3 Jn. y a los hebreos, que es atribuida a Bernabé.

3. En Alejandría Egipto, Clemente entre el 200 y el 210 cita unas dos mil veces textos que hoy forman el N. T. Él tiene como canónicos: los 4 evangelios, todas las epístolas del corpus paulino (incluida Hebr) y el resto de las epístolas menos 3 Jn., 2 Pe. y Sant.

Hacia el año 200, pues, las circunstancias se consideran maduras para que ya funcione un canon bastante formado. Esto parece haber sido causado por el vigor de la fe de los primeros cristianos que, si bien se conformaban con el A. T., empezaron pronto a percibir las diferencias sobre todo en el seno

44. Armand Puig, Los evangelios apócrifos I, Madrid, Ariel, 2008, p. 45. de las iglesias paulinas. Pero en ese lapso, las colecciones de dichos de Jesús habían adquirido un rango análogo a la escritura. ¿Por qué se va formando el canon? Hay varias respuestas a esta pregunta:

1. Por un proceso natural: se van coleccionando recuerdos que se van juntando, esas colecciones de recuerdos van teniendo una autoridad parecida a la del A. T. Finalmente, viene la confirmación eclesiástica a mediados del siglo II.

2. La realización de una Biblia cristiana se debe al hereje Marción y a la iglesia que luchó contra él: a las objeciones de Marción la Iglesia va oponiendo los escritos del N. T. otorgándoles la misma autoridad que al A. T.

Entre los criterios que sirvieron para seleccionar el canon se pueden enumerar los siguientes:

1. La conformidad del contenido del supuesto escrito sagrado con la regla de fe o canon de la fe. Por tanto, es la congruencia teológica del contenido. Esa regla de fe incluía: una fe monoteísta, la fe en Jesús como ser divino, la fe en sus milagros, la fe en el pecado y en Satanás como inductor 
suyo, la fe en la renovación del mundo por Dios, la habitación del Espíritu Santo en el hombre, el amor como mandamiento supremo y la creencia en el juicio final.

2. El segundo criterio es la apostolicidad o vínculo del escrito con los apóstoles.

3. La aceptación del escrito por todos y de manera continua del escrito en cuestión.

\section{Conclusiones}

El canon tardó mucho tiempo en consolidarse: un texto se torna canónico cuando a su alrededor se forja un consenso colectivo basado en la convicción sobre su carácter de escrito inspirado: un texto llega a ser canónico cuando el conjunto de iglesias comparten la certeza de su carácter inspirado. El canon llegó a estar conformado sólo en el siglo IV. Primero se consolidarían uno o dos evangelios y las cartas de Pablo. Para el año 100, la mayoría de los escritos del futuro N.T. ya existen en una forma muy cercana a como los conocemos hoy.

El canon no está herméticamente cerrado. Había discusiones sobre la canonicidad de algunos libros. Al lado de los libros considerados como canónicos o inspirados, aparecen libros sobre los que la comunidad conservó dudas como la Carta a los Hebreos. Pero también sobre el Apocalipsis, por sus interpretaciones milenaristas. Empero, el Códice Claromontanus considera escritos canónicos aquellos debidos a los Padres Apostólicos, como la Carta de Bernabé o El Pastor de Hermas, e incluso algunos escritos apócrifos como los Hechos de Pablo o El Apocalipsis de Pedro, escritos que por ejemplo Eusebio de Cesarea considera no auténticos. Hay, en todo caso, una doble actitud con respecto a los escritos apócrifos: a partir del año 200 nadie se atreverá a añadir un evangelio a la lista de evangelios canónicos pese a que es el tiempo de proliferación de evangelios, por ejemplo los evangelios gnósticos. Hay un escrito del año 367, la Carta pascual de Atanasio de Alejandría, en donde aparece el canon completo, como hoy lo conocemos, cerrado con los veintisiete libros del Nuevo Testamento. ${ }^{45}$

La historia del canon del Nuevo Testamento es un proceso muy complejo y largo que abarca varios tipos de escritura, autoría y funcionalidad de un conjunto de textos que pasa por la rigurosa fase de la tradición oral y, en distintos momentos, más bien tarde que temprano, los va cribando

45. Armand Puig, Los evangelios apócrifos, Madrid, Ariel, 2008. 
hasta que se convierte en escritura a causa de muchas influencias, proyectos e intereses.

\section{Bibliografía}

Bruce, F., 2002, El canon de la escritura, Barcelona, Villadecavalls.

Bultmann, Rudolf, 1995, La historia de la tradición sinóptica, Salamanca, Sígueme.

Bultmann, R.,1967, Die Gescgichte der synoptischen Tradition, Göttingen.

Bultmann, B., 1964, Jesus Christus und die Mythologie, Hamburg, Furche-Verlag.

1968,Jésus. Mythologie et démythologisation, Paris, Ed. de Seuil,

Delcor, M. / F. García Martínez, F. 1982, Introducción a la literatura esenia de Qumrán, Madrid, Cristiandad.

Dibelius, Martín, 1984 La historia de las formas evangélicas, Valencia, EDICEP.

García, Florentino Martínez (Editor y traductor),1992, Textos de Qumrán, Madrid, Trotta.

JohnKloppenborg, John S., 2005, $Q$ el evangelio desconocido, Salamanca, Sígueme.

Macdonald, M. Y., 1994. Las comunidades paulinas, Salamanca, Sígueme.

Marguerat, Daniel, 2008, Introducción al Nuevo Testamento. Su historia, su escritura, su teología, Bilbao, Desclée de Brouwer.

Monasterio, Rafael / Rodríguez Carmona, Antonio,1992, Evangelios sinópticos y Hechos de los apóstoles, Estella, Verbo divino.
Puig, Armand, 2008, Los evangelios apócrifos I, Madrid, Ariel.

Piñero, Antonio (1991), Orígenes del Cristianismo. Antecedentes y primeros pasos, Madrid, Ediciones el Almendro.

Piñero, Antonio, (2006) Guía para entender el Nuevo Testamento, Madrid, Trotta.

Piñero, Antonio / Peláez, Jesús, 1995, El nuevo testamento. Introducción al estudio de las primeros escritos cristianos, Madrid, El Almendro / Fundación Épsilon

Ramos, Felipe F., 1988, El nuevo Testamento I Presentación y contenido, Madrid, Sociedad de educación Atenas.

Schmidt, Karl L., 1969, Der Rahmen der Geschichte Jesu, Darmstadt, Wissenschaftliche, Buchgesellschaft.

Sánchez Bosch, Jordi, 1998, Escritos paulinos, Estella: Verbo Divino.

Ska, Jean Louis, 2004, Cosas nuevas y viejas Mt 13, 52. Páginas escogidas del evangelio de Mateo, Estella: Verbo Divino.

Stanton, G., 1999, ¿La verdad del evangelio? Nueva Luz sobre Jesús y los evangelios, Villatuerta.

Theissen, G. y Merz, A., 1999, El Jesús histórico, Salamanca, Sígueme.

Trebolle Barrera, J., 1998, La Biblia judia y la Biblia cristiana, Madrid, Trotta.

Vanderkam J. y Flint, P., 2008, El significado de los rollos del Mar Muerto, Madrid, Trotta.

Vidal, Senen, 2006, El primer escrito cristiano, Salamanca, Ed. Sígueme.

Vidal,Senén,1996, Las cartas originales de Pablo, Madrid, Trotta. 
